\title{
Kurt Jellinger Prize 2010 for Outstanding Scientific Writing in Neuropathology
}

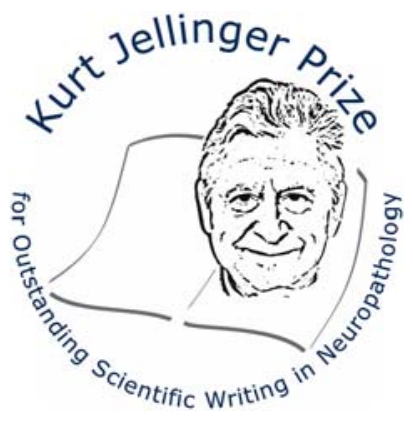

The Kurt Jellinger Prize, sponsored by Springer's Acta Neuropathologica, is aimed at promoting excellence in scientific writing in clinical and experimental neuropathology. It is named after Kurt Jellinger, who has contributed important publications in almost any area of neuropathology and has served as Managing and Executive Editor of Acta Neuropathologica for 29 years.

Since 2005 the prize has been awarded every year to a scientist (preferably but not necessarily being younger than 40 years) who has shown special distinction both in neuropathology, or a related field of neuroscience, and in outstanding scientific writing as exemplified by an unpublished review article submitted to Acta Neuropathologica by the applicant. The submitted review article represents the basis for the prize committee's decision. The prize includes not only money, but also the privileges (and duties) of shaping a neuropathology journal.

The recipient will receive:

- An invitation to join the Editorial Board of Acta Neuropathologica for an initial period of 3 years.
- An invitation to present a lecture at the XVIIth International Congress of Neuropathology where the prize will be awarded. The meeting will take place 11-15 September 2010, in Salzburg, Austria (see http://www.icn2010.org/).

- Expenses for this meeting (traveling, accommodation, registration).

- The sum of $€ 1,000$.

This international prize is open to all scientists of all nationalities. Only self-nominations are considered.

Applicants should submit a review article on any subject that might be of interest to neuroscientists, preferentially of mechanisms of neurological disease as well as a CV, to the Editor-in-Chief of Acta Neuropathologica. Usually, but not necessarily, the subject of this review will focus on the author's research area. The article must have a single author. There are no other formal requirements. While the article of the winner will be published in Acta Neuropathologica, review articles not awarded the Kurt Jellinger Prize will also be considered for publication.

Deadline is 30 April 2010.

Previous recipients have been Robert Hevner, Seattle (2005), Katrin Beyer, Barcelona (2006), Tetsutaro Ozawa, Niigata (2007) and Goran Simic, Zagreb (2008). 